\title{
Synthesis
}

\section{Learning More Effectively from Experience}

\author{
$\underline{\text { Ioan Fazey }}{ }^{1}$ John A. Fazey ${ }^{2}$, and Della M. A. Fazey ${ }^{2}$
}

\begin{abstract}
Developing the capacity for individuals to learn effectively from their experiences is an important part of building the knowledge and skills in organizations to do good adaptive management. This paper reviews some of the research from cognitive psychology and phenomenography to present a way of thinking about learning to assist individuals to make better use of their personal experiences to develop understanding of environmental systems. We suggest that adaptive expertise (an individual's ability to deal flexibly with new situations) is particularly relevant for environmental researchers and practitioners. To develop adaptive expertise, individuals need to: (1) vary and reflect on their experiences and become adept at seeking out and taking different perspectives; and (2) become proficient at making balanced judgements about how or if an experience will change their current perspective or working representation of a social, economic, and biophysical system by applying principles of "good thinking." Such principles include those that assist individuals to be open to the possibility of changing their current way of thinking (e.g., the disposition to be adventurous) and those that reduce the likelihood of making erroneous interpretations (e. g., the disposition to be intellectually careful). An example of applying some of the principles to assist individuals develop their understanding of a dynamically complex wetland system (the Macquarie Marshes in Australia) is provided. The broader implications of individual learning are also discussed in relation to organizational learning, the role of experiential knowledge for conservation, and for achieving greater awareness of the need for ecologically sustainable activity.
\end{abstract}

Key Words: adaptive management, adaptable practitioners, experience, expert, learning, Macquarie Marshes

\section{INTRODUCTION}

Active adaptive management is often suggested as a way of dealing with uncertainty in conservation and resource management (e.g., Walters and Holling 1990, Lee 1999). Using interventions as experiments, managers "learn by doing," with the "active" emphasizing an experimental approach (Walters and Holling 1990). Active adaptive management is based on the premise that knowledge of the system is always incomplete. The system is seen as a moving target, which is continuously evolving because of the human influences on it (Walters and Holling 1990). The results of experiments in these systems are often described as being surprising (e.g., North et al. 1994), thus a primary aim of active adaptive management is to learn something from the experiments, and for scientists to recognize the surprises and pursue their implications (Lee 1999).

An experimental approach prevents "superstitious" learning, where erroneous connections between cause and effect can occur (Levitt and March 1988). This partly arises because environmental and resource problems are most apparent during extreme events, which are usually followed by less extreme events. A problem may, therefore, appear to have been solved, despite the possibility that it occurred because of a particular mix of fluctuating causal factors (Levitt and March 1988). Superstitious learning can also be induced by evaluations of success that are insensitive to the actions taken, particularly when there is a high degree of accountability, and where managers are 
held to standards that have little grounding in ecological science (Levitt and March 1988).

The concept of superstitious learning is partly based on the premise that humans have a limited capacity to understand the complexity of ecological systems. This is true to some extent, because the human mind does not deal well with complex probabilities (Anderson 2001) and with the complex feedback between the different components of dynamic systems (Sterman 2000). However, when searching for objectivity, we often forget that, despite the complexity of our daily lives, we still manage to function effectively. The vast majority of our decisions are informed by our implicit understanding and experience of how the world works (Lakoff and Johnson 1999), not on evidence from controlled experiments. Although experimental evidence is essential (Walters and Holling 1990), the extent of our personal experience is often one of the most important factors influencing the effectiveness of resource management decisions (Woodwell 1989).

Developing the capacity for individuals to be able to learn effectively from their experiences is an important part of building the knowledge and skills in individuals and organizations to do good adaptive management (Kleiman et al. 2000, Salafsky et al. 2002). Therefore, this paper aims to present a way of thinking about how individuals learn to help researchers and practitioners develop expertise in a way that enhances their ability to deal flexibly with new situations. The paper is based on the premise that, if individuals understand how to learn, they will be able to learn more effectively in complex, dynamic, social, economic, and biophysical systems (referred to herein as "environmental systems").

We first explain "learning" from a phenomenographic perspective (i.e., from studies of what learners and teachers can say or demonstrate about their own experiences of learning), and highlight the importance of developing "adaptive expertise." We then review some of the key factors that influence learning, and suggest how individuals can put the ideas into practice. This includes an example of applying the ideas to facilitate understanding about the conservation issues affecting a complex and dynamic wetland. Finally, we briefly consider the broader implications of developing the capacity for individuals to learn more effectively from their experiences.

\section{LEARNING AND EXPERTISE}

\section{What is Learning?}

We adopt the view about learning that comes from phenomenography. In this view, a person's understanding of the physical, social, emotional, and conceptual/intellectual world is taken to be the dynamic relationship between that person and the world, and is, therefore, a product of the individual's experiences in and of the world (Marton and Saljo 1976a, 1976b). With new experiences, the way in which a person perceives and acts in the world changes. Therefore, learning can be considered to be a change in a person's understanding of their place in the world and how they perceive it; i.e., a change in the person-world relationship (Fazey and Marton 2002).

This view of learning has several implications. First, a person's understanding and their learning cannot always be easily distinguished because understanding is directly related to what is learned. Second, because understanding is that which is arrived at by the learner, there may be individual differences in how people understand a system or situation. Third, understanding enables a person to do certain things, and, just as there are different ways of understanding the world, there are variations in what this understanding allows a person to do (Fazey and Marton 2002). This view of learning emphasizes that each person may understand the environmental system they work in differently, because their understanding of the whole of the system is based on a unique set of experiences of how a subset of that system operates.

\section{What is Expertise?}

Research indicates that experts acquire extensive knowledge that affects what they notice, and how they organize, represent, and interpret information. This, in turn, affects their capacity to remember, reason, and solve problems. Therefore, expertise is not just memory and intelligence, or simply the use of general strategies (Bransford et al. 2000). In general, it takes around 10 years to develop expertise in something in the way that is typically discussed in the educational literature (e.g., Chase and Simon 1973, Simon and Chase 1973).

There are six key outcomes from observations about 
how an expert's knowledge differs from that of a novice (from Bransford et al. 2000):

1. Experts recognize features and patterns that are not noticed by novices. For example, chess masters and less experienced, but still extremely good players, show no difference in thinking about the number of possibilities of making a move, or the number of possible counter moves that could be made by their opponents (de Groot 1965). Instead, experts appear to be able to "chunk" together related pieces of information, thereby enhancing short-term memory and decision making (Chase and Simon 1973).

2. Experts organize content knowledge around central ideas, which guide their thinking about certain situations. In physics, for example, an expert's thinking is based around how general principles might be applied to a particular problem. Novices, on the other hand, tend to perceive problem solving as memorizing, recalling, and manipulating equations to get answers (Larkin and Simon 1987). Therefore, it is probably more important to determine a basis for organizing facts, rather than concentrating on trying to retain large amounts of factual detail when beginning to develop understanding about an environmental system.

3. Although experts have acquired vast knowledge, they do not need to search through everything in order to find what is relevant to a particular circumstance or task. Expert knowledge is attached to certain contexts (Simon 1980, Glaser 1992), and it cannot always be easily reduced to isolated facts or propositions.

4. Experts are able to retrieve knowledge effortlessly. This does not mean that experts always accomplish tasks in less time than novices, but fluent retrieval places less demands on conscious attention (Schneider and Shiffrin 1985). For example, novices cannot simultaneously drive a car and hold a conversation. With experience, the application of knowledge about how to drive becomes automated, and less cognitive capacity is required for driving.
5. An expert may not necessarily be good at helping others learn. Expertise can sometimes inhibit teaching, because many experts forget what is easy and what is difficult for the learner.

6. Experts display different degrees of flexibility in being able to adapt and deal with new situations. Although a person may be technically proficient, they may not be able to adapt in a creative way. A hypothetical example is a trapper who demonstrates expertise in keeping a site free of rabbits. In this context, the specific trapping skill may be sufficient to achieve the desired outcome. However, if the desired outcome is to maintain the rabbit population for optimum grazing to conserve flora, more flexibility in their skill is required. Experts who are highly competent and have developed their understanding of something in a way that allows them to flexibly deal with new situations can be described as having developed "adaptive expertise" (see Hatano and Inagaki 1986).

These observations highlight that expert knowledge and understanding can often be difficult to articulate, and that experts may not always be able to explain why they know or do something. Such personal knowledge is referred to as "tacit knowledge" (sensu Polanyi 1958). It is built on our unique experiences of the world, and is often assimilated informally (Boiral 2002). Although tacit knowledge cannot be articulated, it forms the basis of much of an expert's implicit understanding (which has not been, but can be made explicit). Implicit and tacit knowledge have significantly contributed to environmental management. Examples include: helping focus conservation activities to the real causes of a problem (e.g., Fazey et al. submitted), increasing the applicability of research results (Steiner 1998); assisting industry to reduce discharge of pollutants (Boiral 2002), guiding ecosystem management (Olsson and Folke 2001), and determining natural flood regimes (Robertson and McGee 2003).

Experienced and highly skilled people demonstrate expertise by solving problems by using their tacit understanding of the systems they work in. Through such understanding, individuals may recognize emergent properties of a system, and can often make good predictions. For example, subjective 
judgments about extinction risk made by experts were only slightly less accurate than models of population dynamics. Importantly, it only took experts 1-2 hours to make a prediction, compared with 1-2 days using the models (McCarthy et al. 2004). In recognition of the value of expert knowledge, many organizations are now trying to find ways of capturing the expertise of employees who are approaching retirement, or are leaving for other jobs (Holloway 2000).

\section{Expert Understanding of Environmental Systems}

Understanding how we learn is important for anyone who wants to develop expertise or learn how to do something better. In environmental conservation, the role of the practitioner is varied. Nevertheless, most environmental practitioners aim to achieve a better understanding of the environmental system they operate in or intervene with to ensure decisions are appropriate and outcomes are more effective. The particular physical, social, or intellectual skills they learn or use, such as catching feral animals, developing communication skills, or acquiring greater understanding of statistical methods, all contribute to the development of the practitioner's personal understanding of some part of the system.

The concept of adaptive expertise has particular relevance for environmental practitioners who are making management and policy decisions within an endlessly varying, dynamic system. Adaptive experts have a depth of understanding that allows them to use their intellectual, physical, emotional, and social capabilities to identify and interpret changes in systems. Individuals may initially be surprised by major unexpected events, which have the potential to result in abrupt changes in their understanding (e.g., Proust 2004). However, as they develop their ability to learn adaptively, they are no longer "surprised" by unanticipated events. Adaptive experts are able to flexibly and more smoothly translate an experience into better understanding, even when those experiences have not been anticipated. They accept uncertainty, and have greater capacity to act appropriately when faced with unanticipated management outcomes.

We refer to individuals who are able to think and act flexibly as "adaptable practitioners." Experts may demonstrate a variable breadth of expertise, such as a rabbit trapper with a relatively narrow focus compared with an expert manager of a dune system, who might trap rabbits, but also needs other skills and knowledge to be effective. In both cases, however, they can only be described as adaptable practitioners if they demonstrate adaptive expertise.

\section{FACTORS AFFECTING INDIVIDUAL LEARNING}

In this section, we review some of the key factors that affect individual learning. Although studies of learning provide several different perspectives on how to assist individuals to develop adaptive expertise, we restrict our focus to the importance of: (1) practice, (2) variation in practice, and (3) reflection in learning and the importance of "good thinking."

\section{Practice}

Learning how to do something better requires regular practice. In the early stages of learning, a learner is conscious of almost everything, but is often unable to identify what is important. As learning progresses, thinking and behavior are gradually refined, and it becomes increasingly automated until the learner can do what they want while paying little attention to doing it. After extended practice, improvement in even the most complicated routines may not be detected, but there is continued improvement in secondary tasks performed at the same time (Schneider 1985).

There are three striking ways of enhancing practice that supports effective learning. First, actual practice can be complemented and, in some cases, replaced by imagined practice in the form of detailed mental rehearsal or review (e.g., Feltz and Landers 1983, Malouin et al. 2004). Second, practicing making judgments about the performance of a task before and after receiving external feedback can improve any subsequent performances, as long as the individual is aware of a set of understandable, objective criteria by which an attempt or performance can be judged (Wulf and Shea 2003). Third, random experience of variation of a task, or frequent changes that introduce unrelated practice tasks, lead to better retention and improved adaptability than when an individual constantly practices the same thing (Shea and Morgan 1979, Magill 1998) (see below). 


\section{Variation in Practice}

At the end of the initial period of practice, learners who have only practiced a task in the same way outperform those who have had higher levels of variation in the practice. In later tests, however, there is often no difference between the performance of high and low variation groups (Shea and Morgan 1979, Jarus 1994). Importantly, when trying a new variation that neither group has practiced, high-variation practice groups always outperform low-variation practice groups (Fazey and Fazey 1989). That is, those who have experienced variation during practice develop adaptive expertise.

To develop adaptability, there are five aspects of practice that can be varied (Fazey, unpublished manuscript): (1) the intended outcome; (2) the criteria by which the outcome is judged; (3) the way a task is done or experienced; (4) the reason for which the learning or creative task is undertaken; and (5) the perspective a person can take (e.g., van Merrienboer et al. 1997, Pramling 1990), such as a stakeholder who tries to look at a conservation issue from the perspective of other stakeholders (e.g., Lynam et al. 2002). These dimensions of variation are not mutually exclusive and interact in complex ways. Introducing variation in only one or two of these dimensions may, therefore, be sufficient to induce more effective learning (Marton and Booth 1997).

Introducing variation helps to break what phenomenologists call the "natural attitude" - our habitual assumption that what we experience is reality-rather than the attitude that it is reality experienced in a particular way (Fazey and Marton 2002). That is, it helps to demonstrate that what we experience is not the same reality as that which others experience. Trying to look at a problem from different perspectives is, therefore, possibly one of the most crucial elements of variation that needs to be practiced (Marton and Wenestam 1988). People will not only be better learners if they are open to how an experience changes their current understanding, but also if they are open to how others have perceived the same experience.

\section{Reflection and Thinking}

To be effective, practice must be purposeful and fit in an overarching framework that includes planning, monitoring, and reviewing. The usually adopted model is a simplified version of Kolb and Fry's (1975) interpretation of K. Lewin's cyclical account of learning. In this model, the learner moves from active or concrete involvement in an experience to observing and reflecting, through to forming abstract concepts, and then to testing the implications of the concepts in new situations. This is popularized as the "plan, act, review, and try again approach." The metaphor of a moving wheel or a spiral is often used to emphasize continuous change, and the learning that occurs over multiple attempts to achieve a learning goal. With added emphasis on reflection, the model provides a useful template for designing experiences to facilitate learning (e.g., Boud and Miller 1997).

Such feedback-based models stress the need for monitoring the discrepancies between an intention and actual outcomes. In some professions (e.g., branches of caring and medicine), reflection on critical experiences is taken to be an important aspect of both individual learning and the development of a professional knowledge base (e. g., Schön 1996). In such cases, asking personal questions about an incident, like "what was my part in it" and "how did it affect me," can be considered equally important to asking "what happened and why?" There is, however, evidence to suggest that it is more important to be aware of what was done, and what resulted from it than to be aware of the shortcomings of an attempt to do something (Wulf and Shea 2003).

For environmental practitioners, reflection on specific experiences aims to stimulate better understanding about an environmental system. Cognitive scientists take the view that people construct some form of dynamic working representation, or mental model, of how a system operates from their current understanding of that system (O'Connor and McDermott 1997). In developing major shifts in understanding, people must also change their mental models. Although mental models do not fully capture the dynamic learning process, they do provide a useful heuristic to communicate notions of how an individual changes their understanding.

The process of adapting mental models is captured 
in models of double-loop learning (e.g., Sterman 2000). In one loop, a decision is made, acted on, and the results used to inform better decision making. Feedback from the actions in the first loop can also induce change in the mental model, which is represented in the second loop. As our mental models change, we change the structures, strategies, and decision rules that control the decision-making processes in the first loop (Fig. 1).

Our ability to evaluate our mental models is constrained because the tools we design to evaluate our working representations (GIS, scientific research, etc.) are influenced by those same mental models, which affect what we measure, define, and give attention to (Sterman 2000). Humans are also notoriously poor at understanding the dynamic feedback of systems (Sterman 2000), which is made particularly difficult in environmental contexts because outcomes of management often take a long time to become apparent, and are confounded by many other factors (Hinrichsen 2000). Furthermore, humans are very defensive about altering their mental models (Argyris 1985), and change is often resisted until actions or decisions produce serious deleterious outcomes (Proust 2004).

To induce change in our mental models, we must become adept at taking different perspectives by applying ideas like variable and reflective practice (Table 1). Taking different perspectives allows us to vary our experience and question our current understanding. However, we also need to be open to changing our mental model as our understanding of the system develops. To do this, we need to become "good thinkers" (Perkins et al. 2000). Good thinking can be characterized as seven broad thinking dispositions (Table 2). Each disposition has three elements: inclination (a person's felt tendency toward a particular behavior), sensitivity (a person's alertness toward a particular occasion), and capability (a person's ability to follow through with a particular behavior). The "ideal thinker" is disposed toward all of the thinking behaviors, and appropriately exhibits one or more of them depending on the occasion. The theory of good thinking is based on logical arguments and a scattering of empirical evidence for the importance of dispositions. Perkins et al. (2000) argue that the theory raises provocative questions about existing models of thinking, casts new light on controversial issues in the field, connects in interesting ways to findings in other promising areas of cognitive research, and has important implications for the education of good thinking.

As with learning anything, ideas like variable and reflective practice and good thinking can become automated in an adaptable way if practiced with intention (e.g., Palmer and Drake 1997). Practicing applying ideas about learning and good thinking to a wide variety of skills, abilities, and circumstances develops flexibility in dealing with new learning situations. Initially, practicing learning or thinking requires careful analysis and reflection of events and experiences. Eventually, the process becomes more automatic. In the end, an expert learner is able to learn or think skillfully with little more than sporadic self-checking (Pramling 1990).

\section{APPLYING THE IDEAS OF VARIABLE AND REFLECTIVE PRACTICE AND GOOD THINKING}

\section{Developing Understanding about Complex Systems}

To develop individual understanding of environmental systems, the ideas of variable and reflective practice and good thinking should be applied to three main situations:

Whenever we use any technique, display skill, or demonstrate ability

For example, when building a fence for stock management, designing an experiment, evaluating the effectiveness of policy, or conducting an environmental impact assessment. Past performance should be reviewed, then the current performance planned, conducted and monitored to determine what was done and how it might have been done better. Variation can be introduced in many ways, such as by mentally considering how things could have been different, such as whether a fire would have responded differently if the wind had changed. A practitioner never experiences exactly the same situation twice, and variation is always present. However, without active reflection, we become comfortable with the way we do something, reducing our capacity to learn from new situations.

Reflecting on natural variation in the real ecological world

A common cri de coeur is that many environmental 
Fig. 1. Double-loop learning (from Sterman 2000). Feedback from the real world can induce change in mental models. Change in the mental model leads to new goals and decision rules, not just new decisions.

\section{Real World}
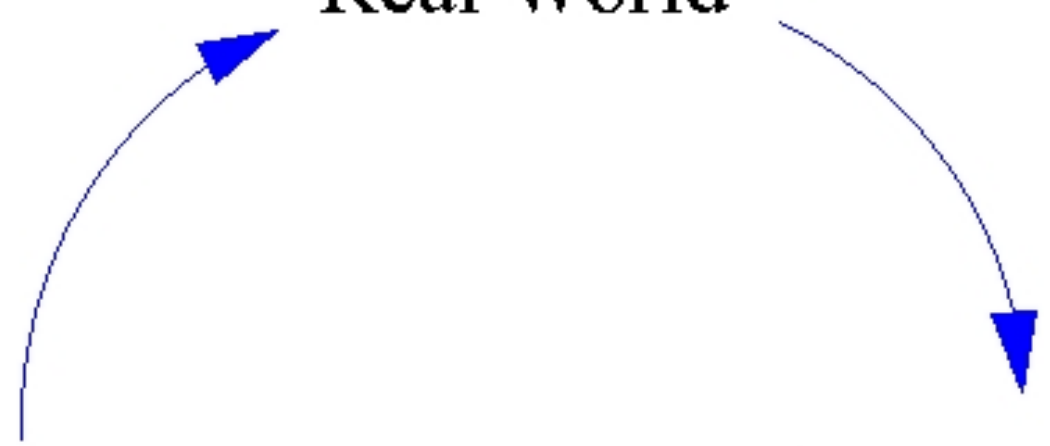

Information

Decisions

\section{Feedback}
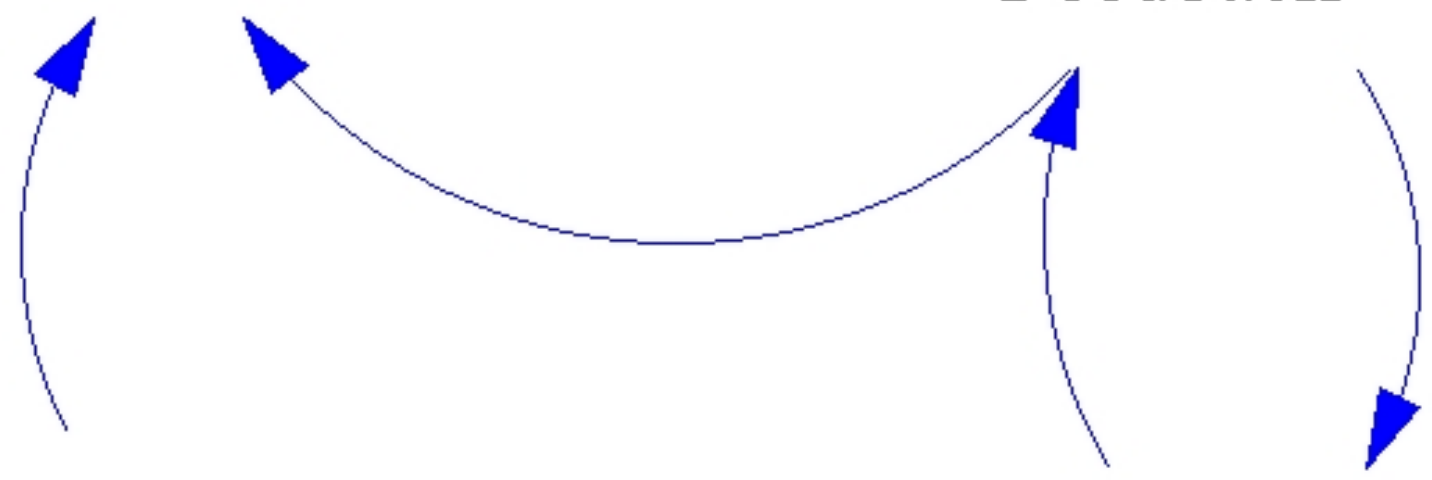

\section{Strategy, Structure, Decision Rules}

\section{Mental Models of real World}

scientists and practitioners do not spend sufficient time directly in an environmental setting (e.g., Noss 1996, Campbell 2003). There are two reasons why this is important. First, we need to ensure that what is being learned about an environmental system is relevant to what we are trying to achieve in the real ecological world. Scientific knowledge stresses objectiveness and distance. However, it is still important to observe events from within the system being studied or managed because spending time in an ecological setting helps to develop our tacit understanding, which guides our questions and how we go about answering them (see Polanyi 1958). As Noss (1996) points out: "abstractions and fancy 
Table 1. Summary of some of the important factors influencing how individuals learn. Note that the points discussed apply equally to both learning a particular skill or ability, and to learning how to learn.

\begin{tabular}{|c|c|}
\hline Factor & Summary \\
\hline \multirow[t]{3}{*}{ Practice } & $\begin{array}{l}\text { With practice, the application of a learned skill or ability can eventually become automatic in a flexible and } \\
\text { adaptive way }\end{array}$ \\
\hline & Actual practice can be complemented and sometimes replaced by detailed mental rehearsal or review \\
\hline & $\begin{array}{l}\text { Practice making judgements improves performance, as long as there is a clear objective and set of criteria } \\
\text { for judging performance }\end{array}$ \\
\hline \multirow[t]{3}{*}{ Variation } & $\begin{array}{l}\text { Variation breaks our tendency to assume that what we experience is reality, not reality experienced in a } \\
\text { particular way }\end{array}$ \\
\hline & Variable practice leads to better retention and develops adaptive expertise \\
\hline & $\begin{array}{l}\text { To develop adaptability, it is possible to vary: (1) the intended outcome, (2) the criteria or precision by } \\
\text { which an outcome is judged, ( } 3 \text { ) the way a task is done or experienced, (4) the reason for doing a task, (5) } \\
\text { the perspective a person can take }\end{array}$ \\
\hline \multirow[t]{3}{*}{ Reflection } & $\begin{array}{l}\text { For effective learning, continuous monitoring of discrepancies between intended and actual outcomes is } \\
\text { required }\end{array}$ \\
\hline & $\begin{array}{l}\text { A number of explicit methods can be used to promote learning. However, having the right attitude by taking } \\
\text { a mindfulness approach to learning is the most important factor influencing learning effectiveness }\end{array}$ \\
\hline & Thinking about our thinking is essential for developing an effective learning attitude (Table 2) \\
\hline
\end{tabular}

technologies are no substitutes for the wisdom that springs from knowing the world and its creatures in intimate, loving detail."

Second, spending time in an environmental setting may also help motivate environmental learning. Whiteman and Cooper (2000) suggest that managers who are physically located outside in their local ecosystems, and who gather management knowledge through first-hand experience, develop both a greater identification with their local ecosystem and have greater commitment to sustainable management practices. Strong personal identification with an environmental system will promote learning because the learning process is more likely to be perceived as being personally important. Such intrinsically motivated learning is more powerful and robust in the face of difficulties than learning that is driven by extrinsic factors, such as rewards or punishments, where a person does something because they have to, rather than because they want to (Deci and Ryan 1985).

Whereas spending time in environmental settings can facilitate the development of understanding of an environmental system, individuals will also enhance learning by actively engaging in the learning process, such as by applying the ideas of variable and reflective practice and good thinking. To do this, it is necessary to actively reflect on observed events and become accustomed to spending field time thinking about what is happening, and how it might be different even if nothing is actually occurring at the time. For example, spending field time thinking about or discussing with others the different ways selective logging might impact a forest will help individuals improve their understanding of that particular forest and its biota.

\section{Developing expertise in exploring the feedback in systems}

This requires practicing dealing with complexity by trying to understand the links between the different components of a system (e.g., specific taxonomic groups or ecological vs. social or economic) rather than always trying to reduce them to immediately 
Table 2. Developing an appropriate learning attitude is influenced by how we think. Good thinking has seven broad dispositions, each with three components (from Pekins et al., unpublished).

\begin{tabular}{|c|c|c|c|}
\hline \multirow[t]{2}{*}{ Disposition } & \multicolumn{3}{|c|}{ Component } \\
\hline & Inclination (examples) & Sensitivity (examples) & Ability (examples) \\
\hline $\begin{array}{l}\text { 1) To be } \\
\text { broad and } \\
\text { adventurous }\end{array}$ & $\begin{array}{l}\text { Tendency to be open- } \\
\text { minded, impulse to probe } \\
\text { assumptions, desire to } \\
\text { tinker with boundaries }\end{array}$ & $\begin{array}{l}\text { Alertness to binariness, } \\
\text { dogmatism, sweeping } \\
\text { generalities, narrow } \\
\text { thinking }\end{array}$ & $\begin{array}{l}\text { Identify assumptions, } \\
\text { empathic and flexible } \\
\text { thinking, to look at things } \\
\text { from other points of view }\end{array}$ \\
\hline $\begin{array}{l}\text { 2) Toward } \\
\text { sustained int- } \\
\text { ellectual cur- } \\
\text { iosity }\end{array}$ & $\begin{array}{l}\text { Zest for inquiry, urge to } \\
\text { find and pose problems, } \\
\text { tendency to wonder }\end{array}$ & $\begin{array}{l}\text { Alertness to unasked } \\
\text { questions, anomalies, } \\
\text { hidden facets, detecting } \\
\text { gaps in knowledge }\end{array}$ & $\begin{array}{l}\text { To observe closely, focus } \\
\text { and persist in a line of } \\
\text { inquiry }\end{array}$ \\
\hline $\begin{array}{l}\text { 3) To clarify } \\
\text { and seek } \\
\text { understanding }\end{array}$ & $\begin{array}{l}\text { Desire to grasp the } \\
\text { essence of things, impulse } \\
\text { to anchor ideas to } \\
\text { experience and seek } \\
\text { connections to prior } \\
\text { knowledge }\end{array}$ & $\begin{array}{l}\text { Alertness to unclarity, } \\
\text { discomfort with } \\
\text { vagueness, a leaning } \\
\text { toward hard questions }\end{array}$ & $\begin{array}{l}\text { Ability to ask pointed } \\
\text { questions and build } \\
\text { complex conceptualizations, } \\
\text { ability to make analogies } \\
\text { and comparisons }\end{array}$ \\
\hline $\begin{array}{l}\text { 4) To plan } \\
\text { and be } \\
\text { strategic }\end{array}$ & $\begin{array}{l}\text { Urge to set goals, make } \\
\text { and execute plans, a } \\
\text { desire to think ahead }\end{array}$ & $\begin{array}{l}\text { Alertness to lack of } \\
\text { direction, lack of } \\
\text { orientation, sprawling } \\
\text { thinking }\end{array}$ & $\begin{array}{l}\text { Ability to formulate } \\
\text { goals, evaluate alternative } \\
\text { modes of approach, make } \\
\text { plans and forecast } \\
\text { possible outcomes }\end{array}$ \\
\hline $\begin{array}{l}\text { 5) To be } \\
\text { intellectually } \\
\text { careful }\end{array}$ & $\begin{array}{l}\text { Urge for precision, a } \\
\text { desire for mental } \\
\text { orderliness, organization, } \\
\text { and thoroughness }\end{array}$ & $\begin{array}{l}\text { Alertness to possibility of } \\
\text { error, disorder and } \\
\text { disorganization, inaccuracy } \\
\text { and inconsistency }\end{array}$ & $\begin{array}{l}\text { Ability to process } \\
\text { information precisely, to } \\
\text { recognize and apply } \\
\text { intellectual standards }\end{array}$ \\
\hline $\begin{array}{l}\text { 6) To seek } \\
\text { and evaluate } \\
\text { reasons }\end{array}$ & $\begin{array}{l}\text { A leaning toward healthy } \\
\text { scepticism, the drive to } \\
\text { pursue and demand } \\
\text { justification, the urge to } \\
\text { discover grounds and } \\
\text { sources }\end{array}$ & $\begin{array}{l}\text { Alertness to evidential } \\
\text { foundations, responsiveness } \\
\text { to superficiality and } \\
\text { overgeneralization }\end{array}$ & $\begin{array}{l}\text { Ability to distinguish } \\
\text { cause and effect, to } \\
\text { identify logical structure, } \\
\text { reason inductively }\end{array}$ \\
\hline $\begin{array}{l}\text { 7) To be } \\
\text { metacognitive }\end{array}$ & $\begin{array}{l}\text { Urge to be cognitively } \\
\text { self aware and to monitor } \\
\text { the flow of one's } \\
\text { thinking, desire to be self } \\
\text { challenging }\end{array}$ & $\begin{array}{l}\text { Alertness to loss of } \\
\text { control of one's thinking, } \\
\text { detection of complex } \\
\text { thinking situations } \\
\text { requiring self monitoring }\end{array}$ & $\begin{array}{l}\text { Ability to exercise control } \\
\text { of mental processes, to } \\
\text { conceive of the mind as } \\
\text { active and interpretive, to } \\
\text { be self evaluative, to } \\
\text { reflect on prior thinking }\end{array}$ \\
\hline
\end{tabular}

manageable pieces. An example is the development of business practices that are resilient over the long term. To be sustainable, corporations need feedback from ecosystems about the ecological impact of their activities (Whiteman et al. 2004). To be effective, however, a shift in culture in the corporate boardroom is required, where individual decision makers accept and understand the complex interactions and feedback between social and natural systems (Chapin and Whiteman 1998).

Practicing building formal simulation models of environmental systems using tools such as causal loop diagrams, or stock and flow models, is particularly useful to induce learning about systems (Sterman 2000). Importantly, all simulation models 
provide individuals with opportunities to vary their perspective, by enabling them to explore how a system might operate with different initial conditions or contextual settings. They also help individuals to articulate their understanding, and allow them to compare their perspective with that of others.

In general, relatively simple ways of thinking about planning, acting, and reflecting may be enough to induce some change in understanding, as long as people have developed the capacity to be open to changing their mental models. Discussing experiences with other people or role playing (e.g., Lynam et al. 2002) can be effective ways to provide alternative perspectives. Building relatively simple models, such as spidergrams, of links between components may also provide a basis upon which detail can be added and integrated. Thus, although considerable effort is required in the initial stages of developing expertise in learning, it is not meant to be an arduous, life-long, learning sentence.

\section{An Example of Applying the Learning Ideas}

Between February and August 2004, research was conducted that aimed to elicit the implicit knowledge of seven on-ground managers about the current conservation problems and issues facing the dynamic Macquarie Marshes (referred to hereafter as the Marshes) in southeastern Australia (see Fazey et al., submitted). At the same time, the ideas about variable and reflective practice were also applied in an attempt to facilitate the development of the onground managers' personal understanding of the environmental system. The case study presented below provides a useful illustration of applying the learning ideas presented in this paper. Although detailed data were not collected that assessed the effectiveness of the approach to induce change in the understanding of the participants, a number of issues were raised that are worthy of reflection.

Research stages for eliciting the implicit knowledge of the on-ground managers to which ideas of variable and reflective practice have been applied

The Marshes are a 220 000-ha ephemeral, wetland system located in the central west of New South Wales. The area is primarily managed privately by landholders, with around 21000 ha managed as a Nature Reserve by the Department of Environment and Conservation (DEC) (see Fazey et al., submitted, for full details). The seven participating on-ground managers were all experts of at least some aspect of managing the complexities of wetland systems, with six having extensive experience of the Marshes. The on-ground managers had a total of 140 years of experience of being involved in the management of water on the Marshes, and 234 years of general experience of working in the Marshes. Some of the managers exhibited a deep, tacit, ecological understanding of the wetland.

A number of research steps were used to elicit the implicit knowledge of the managers (Fig. 2). During the research process, the ideas of variable and reflective practice (Table 1) were also applied to the different research stages by capitalizing on the range of individual and group activities that provided variation in the perspectives taken, the process of data collection, and in the outcomes (Table 3). In the first stage (Fig. 2), the researcher spent 2 months becoming familiar with the issues facing the managers by working as a volunteer with DEC. This provided a period for trust to develop between the participants and the researcher, and ensured that the participants felt they had sufficient control in the process and were confident their knowledge would be communicated appropriately.

In other stages (Fig. 2), repeated opportunities were provided for the participants to articulate their individual understanding (Table 3). Each opportunity was deliberately structured to vary how their expertise was articulated. This not only ensured that the researcher was able to learn about and capture the complexities of the conservation issues, but also enabled variation in the way the participants explored their personal understanding. There were five stages that provided opportunity for variation: (1) Data consisting of simple conceptual links between statements made by a participant were generated in individual interviews. This enabled the initial examination of some of the feedback process occurring in the system. (2) The process was repeated in a second interview where a different aspect of the system was examined. (3) A workshop was held with all participants to identify and discuss the significant historical changes to the environmental system that had contributed to current conservation problems. (4) A preliminary conceptual model describing the environmental system was discussed separately with each participant in a third interview (for a detailed account of the method, see Fazey et al., submitted). 
Fig. 2. Research method used to elicit the expertise of seven on-ground managers of the Marshes. Note that stages 5 and 7 allowed reflection of the process, including assessments that ensured the researcher was adequately reporting the expert understanding of the on-ground managers.

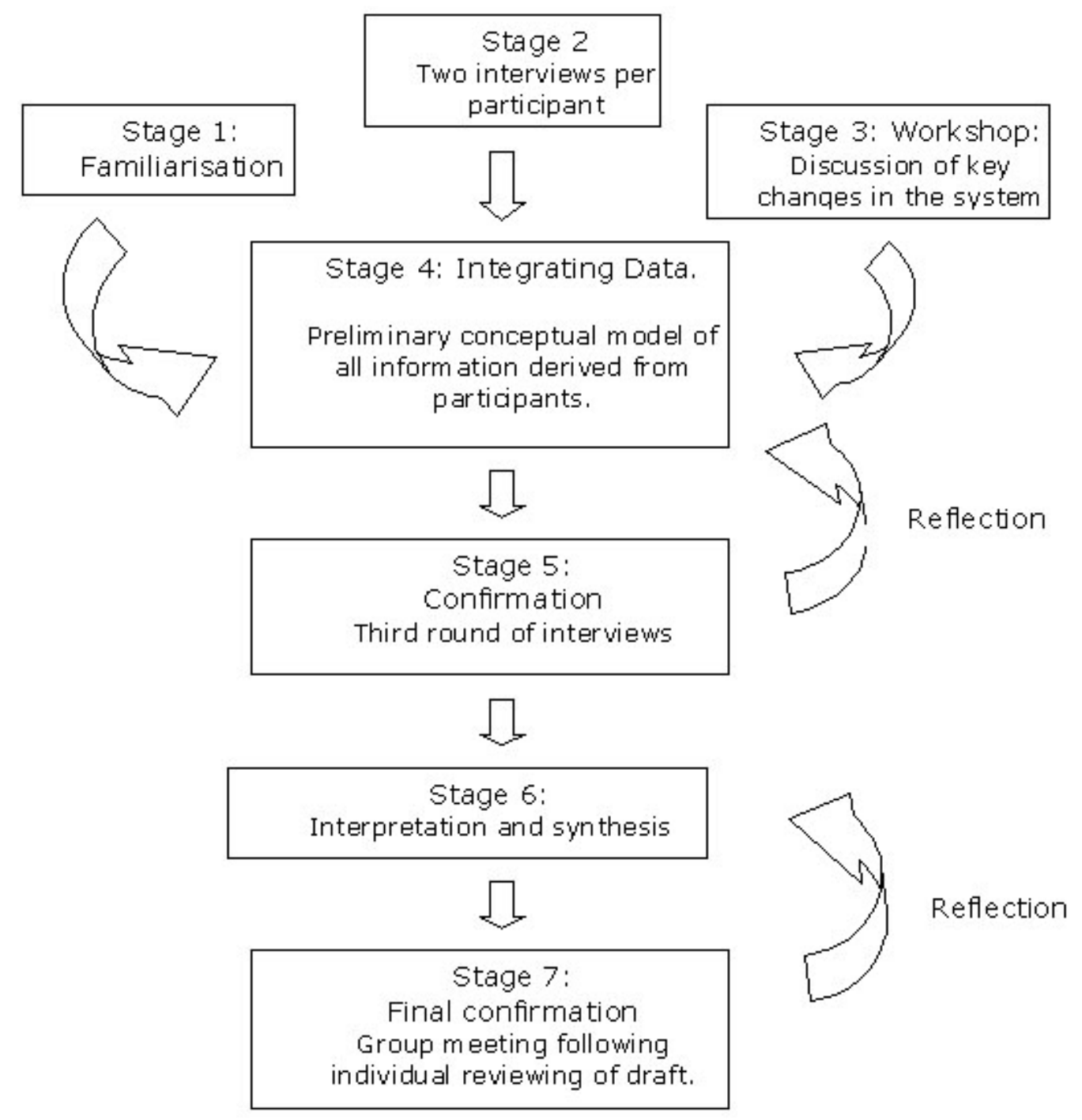

Information flow 
Table 3. Ways in which ideas of learning were applied to help research participants develop their personal understanding of the Marshes environmental system.

\begin{tabular}{ll}
\hline \hline Factor influencing learning & Achieved by: \\
\hline $\begin{array}{l}\text { Providing an appropriate learning } \\
\text { environment where participants felt } \\
\text { motivated to participate }\end{array}$ & $\begin{array}{l}\text { Participants were partly selected on the basis of their interest in participating, i.e., } \\
\text { they participated because they wanted to, or felt it would be useful to them and/or the } \\
\text { Marshes }\end{array}$ \\
$\begin{array}{l}\text { Participants were only asked to provide information on aspects they felt they were } \\
\text { competent to discuss }\end{array}$ \\
$\begin{array}{l}\text { Participants chose which components of the system they discussed } \\
\text { No prior assumptions were made by the researcher about what issues or problems } \\
\text { were most important }\end{array}$
\end{tabular}
$\begin{array}{ll}\text { Practice } & \text { Of studying personal } \\ \text { understanding of the }\end{array}$ Marshes system

Variation By looking at personal understanding of different components of the Marshes system, and sharing perspectives with others

Practicing articulating their understanding through describing the complexities in the first and second interviews, workshops, and providing feedback to the researcher on a preliminary conceptual model in the third interview

Data produced in the first and second interviews were of different components of the Marshes system

Different perspectives were shared at the workshop

The preliminary conceptual model was discussed with individuals at the third interview

Reflection On different stages during the data collection process
At the second interview, the data from the first interview were discussed

At the workshop, data from first and second interviews were presented for reflection by all participants

Reflection on the preliminary group conceptual model with each participant at the third interview

Participants asked in third interview what they had learned from the process and to reflect on whether their understanding had changed
(5) A final meeting was held with all the participants to enable them to collectively give feedback on the accuracy of the conceptual model and the presentation of their expert understanding.

\section{Reflecting on applying the ideas about learning and on the expert knowledge of the participants}

In the third interview, the managers were asked if they had personally gained from the process. The two participants with the least direct experience of the Marshes, who were from outside the core group of managers, felt they had learned a great deal. One of them suggested that they had gained a better understanding of the perspective of the other participants, and that it had been a good opportunity to show their willingness to learn from those with the most experience. Another three individuals suggested that, although they took in very little new information, the process confirmed what they thought they already knew. One manager commented that they sometimes wondered if their 
perception of the issue was valid, given the inaction by relevant government agencies to deal with the conservation problems. Being involved in a process where they shared and discussed their views reinforced their perceptions, and gave them greater confidence in their own expertise and in their understanding of the causes and severity of the conservation problems facing the Marshes.

The sixth participant would not commit to whether the process was personally useful, but acknowledged that the conversations with the primary researcher were influential in developing their thinking and understanding. Finally, only one participant felt they had personally gained very little. However, they acknowledged in the final meeting that the final document (Fazey et al., submitted) was likely to be a useful tool to help articulate their collective expert understanding and add credibility to their expertise.

Although a full evaluation of the application of specific ideas of learning is beyond the scope of this paper, the process appeared to have induced some degree of change in the way participants either understood the Marshes system, or in their perception of their competence in understanding. Importantly, however, the process confirmed the extent of the managers' experiential knowledge. This was most apparent in the workshop, where they worked together in a dynamic and flexible way to provide answers to questions asked by the researchers. In the workshop, it was clear that certain individuals had a more complete understanding about a particular issue than others, but together they generated a collective understanding that was greater than the sum of the parts. As some of the managers put it, they "fed off each other" during the discussion. Their personal in-depth knowledge allowed them to ask pertinent questions when dealing with a topic that was outside their immediate area of expertise, enabling them to tease out the implicit knowledge of those with greater experience.

The expert knowledge of most of the managers was derived from their long-term experience of working and living in the Marshes. They also had a deep and long-standing respect for the natural environment in which they lived and worked, and had a strong personal motivation to learn about and conserve the Marshes and the human community that depended on it. This observation supports the proposed link between ecological respect and a sense of personal identification with a greater commitment to sustainable management practices (Livingston 1994, Whiteman and Cooper 2000).

Observations of the expert understanding of the managers also provide some support to the notion that personal identification with an ecosystem may promote an intrinsic motivation to learn about the ecology of that system. The personal interest of some of the participants to learn appears to have been derived from their economic dependence on an ecologically functional wetland. Without flooding on the Marshes to generate native vegetation growth to feed cattle, cattle grazers would not be able to sustain a living. Such dependence on natural flooding events means that cattle grazers (particularly those that are solely dependent on cattle production) are likely to be more aware of changes in wetland dynamics than individuals involved in other agricultural enterprises.

Compared with agricultural enterprises such as cropping (which are less dependent on flooding), cattle grazers on the Marshes continually receive and react to feedback from water flows entering the wetland. Cattle grazing on the Marshes is also different from other agricultural enterprises that are also heavily dependent on water resources, such as cotton production. Cattle grazing on the Marshes relies on working with, and responding to the variability in the timing, duration, and extent of flooding events. Irrigation enterprises, however, generally depend on reducing risks associated with natural variability in water flows by attempting to control water delivery (e.g., through construction of weirs and dams). Because cattle grazers on the Marshes have such strong links to the variability in water flow, they are more likely to be intrinsically motivated to observe and reflect on the variability in flooding and the response of the wetland to those flooding events. The cattle grazers are, therefore, likely to have built a more in-depth ecological understanding of the Marshes.

Over the last 40 years, since river regulation on the Macquarie River, there have been major changes to the water regime, with significant amounts of water being extracted to support upstream towns and irrigation industries (Kingsford and Thomas 1995). This has resulted in a major change in the ecological character of the Marshes, with direct consequences for the livelihood of many individuals on the wetland (Fazey et al., submitted). In the case of the Marshes, the expert understanding of many of the 
cattle grazers, therefore, has particular relevance and value for providing insights into how much upstream water extraction is likely to be ecologically sustainable.

The economic dependence of some of the managers on the wetland clearly influenced their perspective and their own understanding of the Marshes, particularly when they were exposed to stakeholders with radically different views of how best to use river water. However, many other stakeholders in the Macquarie Valley lack the long-term, embedded, ecological knowledge of the Marshes. When it came to questions about its management, the on-ground managers were adamant that the wetland was under serious threat of ecological collapse. To find effective solutions, the water delivery problems occurring beyond the geographical boundaries of the Marshes needed to be dealt with (Fazey et al., submitted).

\section{IMPLICATIONS OF MORE EFFECTIVE INDIVIDUAL LEARNING}

\section{Individual to Group and Organizational Learning}

Many of the characteristics of a "high quality" learning organization (Table 4) revolve around notions of openness and freedom of expression (Bapuji and Crossan 2004). To achieve such a learning culture, members of an organization must also aspire to such goals. In our view, personal characteristics, such as integrity, humility, and openness to criticism and change, are necessary for an individual "ideal learner" to be able to take and be open to different perspectives (see also Antonacopoulou (2004) for a discussion of the characteristics of good scholarship). Individuals with such characteristics will naturally engender an environment in which others can learn. Thus a high quality learning culture is only likely to be possible if individual members are also willing to engage in learning, and if they have developed the capacity to learn effectively.

Considerable emphasis is placed on the importance of leaders who can facilitate the learning of others (Richter 1998, Ramus and Steger 2000, Olsson et al. 2004, Naot et al. 2004, Rushmer et al. 2004). In formal organizations (e.g., corporations or recognized institutions), managers influence subordinates by role modeling, defining goals, allocating rewards, distributing resources, communicating organizational norms and values, structuring work group interactions, conditioning subordinates' perceptions of the work environment, and influencing the processes and procedures used (Ramus and Steger 2000). Even though most leaders do not view themselves as facilitators of learning (Bapuji and Crossan 2004), these influences directly affect the learning opportunities of others (Ramus and Steger 2000).

Targeting leaders may therefore be a good place to begin to develop a culture of learning within an organization (Rushmer et al. 2004). For example, attempts are being made to change the culture within the UK National Health Service so that it can learn better from, and reduce the number of, adverse incidents affecting patients and staff. Managers have first been assisted to gain a fuller understanding of learning as a process of change (Jones et al. 2005a), and have then been supported by mechanisms that help them work and learn more effectively as individuals or in groups (Jones et al. 2005b).

Although it is generally accepted that it is the individuals who learn and not the organization (Miner and Mezias 1996), only focusing on individuals means that the social context of learning in which the individuals are embedded can be neglected (Richter 1998). Thus, in the interpretive perspective of organizational learning, learning is considered to be a social practice (Ortenblad 2002). To understand the way information travels through an organization, the relationships between individuals and the communities within the organization also need to be understood (Richter 1998). Individuals are considered to make sense of the world by communicating and using language and symbols that allow them to collectively invent and reinvent a meaningful order (i.e., "sensemaking"; sensu Weick 1995). Actions are then made in accordance with that particular interpretation of reality (Westley et al. 2002). That is, the organizational learning is considered to be context dependent (Ortenblad 2002).

The interpretive perspective of organizational learning sees learning as a never-ending process (Blackler 1995), which is an important perspective when trying to manage environmental systems adaptively. The perspective also does not assume that organizational learning is confined to a formal 
Table 4. Hypothetical characteristics of a high quality learning organization (from Lipshitz et al. 2002, Naot et al. 2004).

\section{Characteristic of Learning Requirement Organization (LO)}

LO achieves desired management outcomes

LO employs processes that are likely to produce effective learning
LO sets (or is set in) a context where learning is most likely to occur
The organization produces desired outcomes or averts undesired outcomes by learning
Captures notions of single- and double-loop learning

Transparency

Integrity

Issue orientation

Inquiry

Accountability
Where examination of sensitive issues and reframing of assumptions, values and goals can occur

Willingness to expose one's thoughts and actions to others in order to receive feedback

Willingness to seek and provide information regardless of its implications

Focusing on the relevance of information to the issue under consideration regardless of the social standing, rank, source, or

Persisting in investigation until full understanding is achieved

Willingness to assume responsibility for learning and for the implementation of lessons learned recipient

Reciprocal commitment between the organization and its members

Commitment of the organization's leadership to learning and its tolerance for error

An appropriate task structure and proximity to the core tasks of the organization

High cost of potential error (i.e., learning is more likely to occur if cost of error is high)

An environment of uncertainty (i.e., learning is more likely to occur where there is a high degree of uncertainty of achieving desired management outcomes) organization, such as a corporation or recognized institution (Araujo 1998). This is particularly relevant for environmental practice where much of the learning occurs in loosely defined organizations, such as in the group of Marshes managers. In this case, information flowed into the group through individuals with external experience, and was then interpreted collectively through interactions between the members. This gave rise to a unique collective understanding of how and why the wetland was changing (Fazey et al., submitted).

This suggests that, whereas improving the capacity of individuals to learn is essential for building a learning culture, the resulting learning processes and knowledge will not only be confined to particular individuals within a group or organization. Collaboration between individuals is, therefore, necessary to gain a fuller understanding of dynamic environmental systems (Olsson et al. 2004), and social learning processes increase the capacity of organizations to respond to feedback from the environment to ensure that human actions are sustainable (Berkes et al. 2003). 
Fig. 3. Experiments and other experiences may stimulate change in our mental model as we develop understanding, but our understanding and mental models also influence the questions we ask, how we conduct an experiment, and how we analyze and perceive the results.

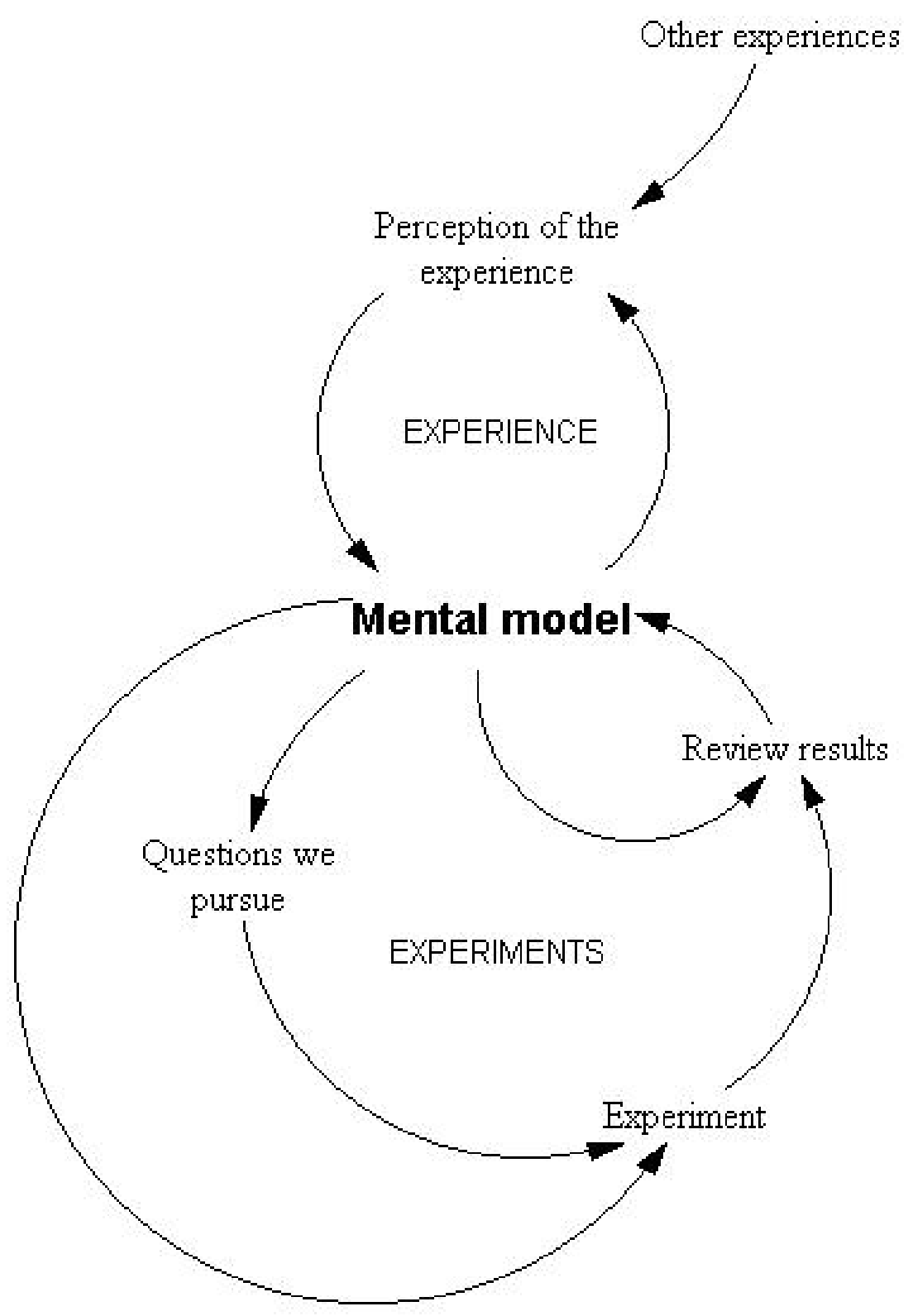


Table 5. Some of the differences between expert and experimental knowledge highlighted by the characteristics of expertise and individual learning.

\begin{tabular}{|c|c|c|}
\hline & Expert knowledge & Experimental knowledge \\
\hline Perspective & Greater capacity for a holistic perspective & Greater capacity for a reductionist perspective \\
\hline Historical perspective & $\begin{array}{l}\text { Has some capacity to take into account the } \\
\text { historical trajectory of something in order to } \\
\text { make better predictions about the future by } \\
\text { interpreting the present with respect to past } \\
\text { experiences (Polanyi 1958). For environmental } \\
\text { systems, this requires extensive experience of } \\
\text { the same phenomenon or system (e.g., some of } \\
\text { the managers of the Marshes). }\end{array}$ & $\begin{array}{l}\text { Has less capacity to take into account the } \\
\text { influence of a historical trajectory because } \\
\text { predictions are based only on what is occurring } \\
\text { in the present. }\end{array}$ \\
\hline $\begin{array}{l}\text { Learning from long- } \\
\text { term outcomes }\end{array}$ & $\begin{array}{l}\text { Less capacity to learn from interventions whose } \\
\text { outcomes take a long time to become apparent } \\
\text { because an individual's experience is finite and } \\
\text { relies more on immediate feedback }\end{array}$ & $\begin{array}{l}\text { Has greater capacity to learn from interventions } \\
\text { that have long-term outcomes because } \\
\text { experiments can run over long periods of time }\end{array}$ \\
\hline $\begin{array}{l}\text { Dealing with } \\
\text { confounding factors }\end{array}$ & $\begin{array}{l}\text { Has less capacity to deal with confounding } \\
\text { factors when trying to distinguish between } \\
\text { cause and effect }\end{array}$ & $\begin{array}{l}\text { Has greater capacity to deal with confounding } \\
\text { factors when trying to distinguish between cause } \\
\text { and effect }\end{array}$ \\
\hline Accessibility & $\begin{array}{l}\text { Difficult for others to access and pick up } \\
\text { because it is either inarticulate (tacit), or very } \\
\text { difficult to articulate (implicit) }\end{array}$ & $\begin{array}{l}\text { Easier for others to access and pick up because it } \\
\text { is formalized and made explicit }\end{array}$ \\
\hline Requirement & $\begin{array}{l}\text { Requires experimental knowledge as a check } \\
\text { and balance to ensure accurate connections } \\
\text { between cause and effect }\end{array}$ & $\begin{array}{l}\text { Requires expert knowledge to identify } \\
\text { appropriate questions, interpret results and } \\
\text { maintain a more holistic perspective }\end{array}$ \\
\hline
\end{tabular}

\section{The Complementary Role of Experiential and Experimental Knowledge}

Relying on experience to inform decisions has both advantages and disadvantages when compared with using experiments, and both experience and experiments are essential for effective environmental practice, and can play a complementary role (Table 5). However, it is often difficult to separate their relative influence in making decisions. The majority of our decisions are predominantly governed by our implicit and tacit understanding of how the world operates (Lakoff and Johnson 1999). This influences the experimental questions we pursue, how we conduct the experiment, and how we analyze the results. The results may alter our understanding and allow us to adapt our mental model (Fig. 3). Other experiences may also influence our understanding, but our understanding also influences what we learn from, and how we perceive, those experiences (Fig. 3). When we make a decision, the results of research are, therefore, combined with the experience of doing the research, the way we interpret the results, and our personal, environmental, and educational experience (e.g., Fazey and McQuie, in press).

The key to improving personal understanding of a system from both experience and the results of experiments is to develop the ability to take different perspectives and learn to become open to how they might affect our mental models. To do this, applying ideas like variable and reflective practice (Table 1) and good thinking (Perkins et al. 2000, Table 2) will be necessary.

\section{Achieving Greater Awareness of the Need for Ecological Sustainability}

Beliefs, worldviews, and dogma continually reinforce actions that are detrimental to the environment (e.g., Barlow and Clarke 2002, Fazey et al., submitted), and people are becoming 
increasingly dissociated from nature (Glendinning 1995, Metzner 1995). Both of these issues are potentially contributing to reinforcing a lack of concern about the seriousness of environmental problems (Kempton and Holland 2003, Fazey et al., submitted). To break reinforcing cycles of perception, individuals need exposure to experiences that will help them challenge their current ways of thinking. This emphasizes the importance of environmental education programs and, given that most people are often forced to find their own ways to learn during the mainstream educational process, it also highlights the need for greater consideration to be given to teaching people how to learn. Increasing the capacity of people to be open to other perspectives could facilitate an increase in awareness of the link between an individual's behavior and the global environmental and social problems. One of the keys to achieving greater environmental sustainability is, therefore, to find ways to provide people with experiences that help them develop a deeper and longer-lasting connection with nature (e.g., Cohen 1997), and then help them to translate such a connection into more ecologically sustainable activities (Cohen 2000).

\section{CONCLUDING REMARKS}

This paper acknowledges the importance of experiential knowledge for effective conservation research and practice. It is not, however, intended to be an argument for using experience as a replacement for appropriate research to inform decisions or for developing individual understandings of environmental systems. Instead, it is a plea for increased rigor in using what we know about turning experience into more effective learning.

This paper has highlighted that it is possible to greatly improve how we learn as individuals. In current educational settings, students are rarely taught how to learn, and learning is often just expected to "happen" during the educational process. Thus, the ideas presented may seem simple, but they have profound implications for educational and professional development. Giving greater consideration to applying ideas about learning from experiences to environmental practice would not only result in more adaptable practitioners with an inquisitiveness and ability to learn, but would also result in more people who were mindful that their view of the world is only one perspective of many.
Responses to this article can be read online at: http://www.ecologyandsociety.org/vollo/iss2/art4/responses/

\section{Acknowledgments:}

We thank the Coonabarabran and Dubbo offices of $D E C$ and the research participants for their support and hospitality. B. Newell, K. Sherrin, J. Fischer, D. Lindenmayer, and $S$. Dovers provided valuable comments on earlier versions of the manuscript. $D$. Lindenmayer and the Centre for Resource and Environmental Studies provided research funds and DEC provided in-kind support. I. Fazey was supported by an EE Scholarship from the Australian National University.

\section{LITERATURE CITED}

Anderson, J. L. 2001. Stone age minds at work on $20^{\text {th }}$ century science: how can cognitive psychology inform conservation biology. Conservation Biology in Practice 2:20-27.

Antonacopoulou, E. 2004. On the virtues of practising scholarship - a tribute to Chris Argyris, a "timeless learner." Management Learning 35:381-395.

Araujo, L. 1998. Knowing and learning as networking. Management Learning 29:317-336.

Argyris, C. 1985. Strategy, change, and defensive routines. Pitman, Boston, Massachussetts, USA.

Bapuji, H., and M. Crossan. 2004. From questions to answers: reviewing organizational learning research. Management Learning 35:397-417.

Barlow, M., and T. Clarke. 2002. Blue gold: the battle against corporate theft of the world's water. Earthscan Publications Ltd., London, UK.

Berkes, F., J. Colding, and C. Folke. 2003. Navigating social-ecological systems: building resilience for complexity and change. Cambridge University Press, Cambridge, UK.

Blackler, F. 1995. Knowledge, knowledge work 
and organizations: an overview and interpretation. Organization Studies 16:1021-1046.

Boiral, O. 2002. Tacit knowledge and environmental management. Long Range Planning 35:291-317.

Boud, D., and N. Miller. 1997. Working with experience: animating learning. Routledge, London, UK.

Bransford, J. D., A. L. Brown, and R. R. Cocking. 2000. How people learn: brain, mind, experience, and school. National Academy Press, Washington, D.C., USA.

Campbell,A. 2003. Learning to live with fire. Pages 243-247 in G. Cary, D. Lindenmayer, and S. Doves, editors. Australia burning: fire ecology, policy and management issues. CSIRO Publishing, Collingwood, Victoria, Australia.

Chapin, F. S., and G. Whiteman. 1998. Sustainable development of the boreal forest: interaction of ecological, social, and business feedbacks. Ecology and Society 2(2):12. (Online.) URL:

http://www.ecologyandsociety.org/vol2/iss2/art12/

Chase, W. G., and H. A. Simon. 1973. Perception in chess. Cognitive Psychology 4:55-81.

Cohen, M. J. 1997. Reconnecting with nature. Ecopress, Corvallis, Oregon, USA.

Cohen, M.J. 2000. Einstein's world: educating and counseling with nature. The natural systems thinking process. Project Nature Connect, Friday Harbor, Washington, USA.

Deci, E. L., and R. M. Ryan. 1985. Intrinsic motivation and self-determination in human behavior. Plenum Press, New York, New York, USA.

de Groot, A. D. 1965. Thought and choice in chess. Mouton, The Hague, Netherlands.

Fazey, D. M. A., and J. A. Fazey. 1989. Modification of transfer effects in different practice schedules-an extension of the variability hypothesis. Journal of Human Movement Studies 17:239-258.
Fazey, I., and A. McQuie. In press. Applying ecological theory for conservation management. Ecological Management and Restoration.

Fazey, I., K. Proust, B. Newell, and B. Johnson. Submitted. Eliciting the implicit knowledge of onground managers: the Macquarie Marshes as a case study. Ecology and Society.

Fazey, J. A., and F. Marton. 2002. Understanding the space of experiential variation. Active Learning in Higher Education 3:234-250.

Feltz, D. L., and D. M. Landers. 1983. The effects of mental practice on motor skill learning and performance - a meta-analysis. Journal of Sport Psychology 5:25-57.

Glaser, R. 1992. Expert knowledge and processes of thinking. Pages 63-75 in D. F. Halpern, editor. Enhancing thinking skills in the sciences and mathematics. Erlbaum, Hillsdale, New Jersey, USA.

Glendinning, C. 1995. Technology, trauma, and the wild. Pages 41-54 in T. Roszak, M. E. Gomes, and A. D. Kanner, editors. Ecopsychology. Sierra Club Books, San Francisco, California, USA.

Hatano, G., and K. Inagaki. 1986. Two courses of expertise. Pages 262-272 in H. Stevenson, H. Azuma, and K. Hakuta, editors. Child Development and Education in Japan. W.H. Freeman, New York, New York, USA.

Hinrichsen, R.A. 2000. Are there scientific criteria for putting short-term conservation ahead of learning? No. Conservation Ecology 4(1):r7. (Online.) URL:

http://www.ecologyandsociety.org/vol4/iss1/resp7/

Holloway, P. 2000. How to protect knowledge from walking out the door. Workforce Magazine (Online.) URL:

http://www.workforce.com/archive/article/22/07/11. php.

Jarus, T. 1994. Motor learning and occupationaltherapy-the organization of practice. American Journal of Occupational Therapy 48:810-816.

Jones, D., E. Bartholomew, and J. Fazey. 2005a. 
The changing culture in risk management: risk-e learning. Research Institute for Enhancing Learning, School of Education, University of Wales, Bangor, Wales, UK.

Jones, D., E. Bartholomew, and C. Minas. 2005 b. Developing the learning organization through learning communities: the risk-e project. Research Institute for Enhancing Learning, School of Education, University of Wales, Bangor, Wales, UK.

Kempton, W., and D. C. Holland. 2003. Identity and sustained environmental practice. Pages 317341 in S. Clayton and S. Opotow, editors. Identity and the natural environment. Massachusetts Institute of Technology, Cambridge, Massachussetts, USA.

Kingsford, R. T., and R. F. Thomas. 1995. The Macquarie Marshes in arid Australia and their waterbirds: a 50-year history of their decline. Environmental Management 19:867-878.

Kleiman, D. G., R. P. Reading, B. J. Miller, T. W. Clark, J. M. Scott, J. Robinson, R. L. Wallace, J. Cabin, and F. Felleman. 2000. Improving the evaluation of conservation programs. Conservation Biology 14:356-365.

Kolb, D. A., and R. Fry. 1975. Toward an applied theory of experiential learning. Pages 33-58 in C. Cooper, editor. Theory of group processes. Doubleday and Company, New York, New York, USA.

Lakoff, G., and M. Johnson. 1999. Philosophy in the flesh: the embodied mind and its challenge to western thought. Basic Books, New York, New York, USA.

Larkin, J. H., and H. A. Simon. 1987. Why a diagram is (sometimes) worth 10000 Words. Cognitive Science 11:65-99.

Lee, K. N. 1999. Appraising adaptive management. Conservation Ecology 3(2):3. (Online.) URL: http://www.ecologyandsociety.org/vol3/iss2/art3/.

Levitt, B., and J. G. March. 1988. Organizational learning. Annual Review of Sociology 14:319-340.

Lipshitz, R., M. Popper, and V. Friedman. 2002. Facets of organizational learning. Journal of
Applied Behavioral Science 38:78-98.

Livingston, J. A. 1994. Rogue primate: an exploration of human domestication. Key Porter, Toronto, Ontario, Canada.

Lynam, T., F. Bousquet, C. Le Page, P. d'Aquino, O. Barreteau, F. Chinembiri, and B. Mombeshora. 2002. Adapting science to adaptive managers: spidergrams, belief models, and multiagent systems modeling. Conservation Ecology 5 (2):24. (Online.) URL:

http://www.ecologyandsociety.org/vol5/iss2/art24/

Magill, R. A. 1998. Motor learning: concepts and applications. McGraw-Hill, Boston, Massachussetts, USA.

Malouin, F., S. Belleville, C. L. Richards, J. Desrosiers, and J. Doyon. 2004. Working memory and mental practice outcomes after stroke. Archives of Physical Medicine and Rehabilitation 85:177183.

Marton, F., and S. Booth 1997. Learning and awareness. Lawrence Erlbaum Associates, Malwah, New Jersey, USA.

Marton, F., and R. Saljo. 1976a. Qualitative differences in learning. 1. Outcome and process. British Journal of Educational Psychology 46:4-11.

Marton, F., and R. Saljo. 1976b. Qualitative differences in learning. 2. Outcome as a function of learners conception of task. British Journal of Educational Psychology 46:115-127.

Marton, F., and C. G. Wenestam. 1988. Qualitative differences in retention when a text is read several times. Pages 370-376 in M. M. Gruneberg, P. E. Morris, and R. N. Sykes, editors. Practical aspects of memory: current research and issues. Wiley, Chichester, UK.

McCarthy, M. A., D. Keith, J. Tietjen, M. A. Burgman, M. Maunder, L. Master, B. W. Brook, G. Mace, H. P. Possingham, R. Medellin, S. Andelman, H. Regan, T. Regan, and $M$. Ruckelshaus. 2004. Comparing predictions of extinction risk using models and subjective judgement. Acta Oecologica-International Journal of Ecology 26:67-74. 
Metzner, R. 1995. The psychopathology of the human-nature relationship. Pages 55-67 in $T$. Roszak, M. E. Gomes, and A. D. Kanner, editors. Ecopsychology. Sierra Club Books, San Francisco, California, USA.

Miner,A. S., and S. J. Mezias. 1996. Ugly duckling no more: pasts and futures of organizational learning research. Organization Science 7:88-99.

Naot, Y. B. H., R. Lipshitz, and M. Popper. 2004. Discerning the quality of organizational learning. Management Learning 35:451-472.

North, S. G., D. J. Bullock, and M. E. Dulloo. 1994. Changes in the vegetation and reptile populations on Round-Island, Mauritius, following eradication of rabbits. Biological Conservation 67:21-28.

Noss, R. F. 1996. The naturalists are dying off. Conservation Biology 10:1-3.

O'Connor, J., and I. McDermott 1997. The art of systems thinking. Thorsons, London, UK.

Olsson, P., and C. Folke. 2001. Local ecological knowledge and institutional dynamics for ecosystem management: a study of Lake Racken Watershed, Sweden. Ecosystems 4:85-104.

Olsson, P., C. Folke, and F. Berkes. 2004. Adaptive comanagement for building resilience in socialecological systems. Environmental Management 34:75-90.

Ortenblad, A. 2002. Organizational learning: a radical perspective. International Journal of Management Reviews 4:87-100.

Palmer, C., and C. Drake. 1997. Monitoring and planning capacities in the acquisition of music performance skills. Canadian Journal of Experimental Psychology-Revue canadienne de psychologie experimentale 51:369-384.

Perkins, D., E. Jay, and S. Tishman. 2000. A dispositional theory of learning. (Online.) URL: http://learnweb.harvard.edu/alps/thinking/docs/merrill. $\underline{\mathrm{htm}}$.

Polanyi, M. 1958. Personal knowledge: towards a post-critical philosophy. Routledge and Kegan Paul, London, UK.
Pramling, I. 1990. Learning to learn. Springer Verlag, New York, New York, USA.

Proust, K. 2004. Learning from the past for sustainability: towards an integrated approach. Dissertation. Centre for Resource and Environmental Studies, Australian National University, Canberra, Australia.

Ramus, C. A., and U. Steger. 2000. The roles of supervisory support behaviors and environmental policy in employee "ecoinitiatives" at leading-edge European companies. Academy of Management Journal 43:605-626.

Richter, I. 1998. Individual and organizational learning at the executive level-towards a research agenda. Management Learning 29:299-316.

Robertson, H. A., and T. K. McGee. 2003. Applying local knowledge: the contribution of oral history to wetland rehabilitation at Kanyapella Basin, Australia. Journal of Environmental Management 69:275-287.

Rushmer, R., D. Kelly, M. Lough, J. E. Wilkinson, and H. T. O. Davies. 2004. Introducing the Learning Practice-III. Leadership, empowerment, protected time and reflective practice as core contextual conditions. Journal of Evaluation in Clinical Practice 10:399-405.

Salafsky, N., R. Margoluis, K. H. Redford, and J. G. Robinson. 2002. Improving the practice of conservation: a conceptual framework and research agenda for conservation science. Conservation Biology 16:1469-1479.

Schneider, W. 1985. Toward a model of attention and the development of automatic processing. Pages 474-492 in I. Posner and O. S. M. Martin, editors. Attention and performance XI. Erlbaum, Hillsdale, New Jersey, USA.

Schneider, W., and R. Shiffrin. 1985. Categorization (restructuring) and automatization -2 separable factors. Psychological Review 92:424-428.

Schön, D. A. 1996. Educating the reflective practitioner: toward a new design for teaching and learning in the professions. Jossey-Bass, Inc., San Francisco, California, USA. 
Shea, J. B., and R. L. Morgan. 1979. Contextual interference effects on the acquisition, retention, and transfer of a motor skill. Journal of Experimental Psychology-Human Learning and Memory 5:179-187.

Simon, H.A. 1980. Problem solving and education. Pages 81-96 in D. T. Tuma and R. Reif, editors. Problem solving and education: issues in teaching and research. Erlbaum, Hillsdale, New Jersey, USA.

Simon, H. A., and W. G. Chase. 1973. Skill in chess. American Scientist 61:394-403.

Steiner, K. G. 1998. Using farmers' knowledge of soils in making research results more relevant to field practice: experiences from Rwanda. Agriculture Ecosystems \& Environment 69:191200.

Sterman, J. D. 2000. Business dynamics-systems thinking and modeling for a complex world. McGraw Hill, Boston, Massachussetts, USA.

van Merrienboer, J. J. G., M. B. M. de Croock, and O. Jelsma. 1997. The transfer paradox: effects of contextual interference on retention and transfer performance of a complex cognitive skill. Perceptual and Motor Skills 84:784-786.

Walters, C. J., and C. S. Holling. 1990. Large-scale management experiments and learning by doing. Ecology 71:2060-2068.

Weick, K. 1995. Sensemaking in organizations. Sage Publications, Thousand Oaks, California, USA.

Westley, F., S. R. Carpenter, W. A. Brock, C. S. Holling, and L. H. Gunderson. 2002. Why systems of people and nature are not just social and ecological systems. Pages 103-120 in L. H. Gunderson and C. S. Holling, editors. Panarchy: understanding transformations in human and natural systems. Island Press, Washington D.C., USA.

Whiteman, G., and W. H. Cooper. 2000. Ecological embeddedness. Academy of Management Journal 43:1265-1282.

Whiteman, G., B. C. Forbes, J. Niemela, and F.
S. Chapin. 2004. Bringing feedback and resilience of high-latitude ecosystems into the corporate boardroom. Ambio 33:371-376.

Woodwell, G. M. 1989. On causes of biotic impoverishment. Ecology 70:14-15.

Wulf, G., and C. H. Shea. 2003. Feedback: the good, the bad, and the ugly. Pages 121-144 in M. Williams, N. Hodges, M. Scott, and M. Court, editors. Skill acquisition in sport: research, theory and practice. Routledge, London, UK. 